\title{
COPIM
}

\section{Library Support for OA Books Workshop: the Scandinavian perspective}

\section{Agata Morka}

Published on: Oct 06, 2020

DOI: 10.21428/785a6451.ebae812c

License: Creative Commons Attribution 4.0 International License (CC-BY 4.0). 
As part of the projects conducted for the COPIM Work Package 2 (Revenue Infrastructures and Management Platform). and OPERAS-P Work Package 6 (Innovation), we are continuing a series of European-based workshops, aiming at gaining a better understanding of the national-specific issues surrounding collective funding for OA books from a library perspective. The third online workshop took place on September 30th. This time we travelled (virtually) north and gathered together representatives of four Nordic countries: Finland, Norway, Sweden and Denmark were present. Equipped with coffee and wrapped in fair isle sweaters, we spent a Wednesday afternoon discussing how one can develop collaborative funding models for OA books that would work in the cold Nordic climate.

\section{Trust me, I am yet another OA books initiative}

Nordic countries are no strangers to open science discussions; in Europe they are leading the way in implementing OA mandates on a national scale. It became apparent during the workshop that any new OA books-related project, in order to be successful, needs to take into account this broader national dialogue and tap into it, showing how it would enhance the national OA missions.

On the other hand, some of the workshop participants reported a certain overdose of OA-related projects that they need to deal with, assess or participate in on a daily basis. Given this fluency in the OA language, any new initiative in that field needs to come across as trustworthy for the Nordic decision makers in order for them to be inclined to invest in it. There were strong voices calling for transparency and inclusiveness of governance structures and diversity of stakeholders to be involved in them.

\section{Who's the fairest of them all?}

The question of so called "recognition" presented itself as one of recurring themes and it became clear that any new OA books initiative will need to face the reality of existing evaluation systems, with their lists of desirable publishing outlets. In the Nordic countries, there are official lists, with separate ratings for journals and for book publishers (Norwegian one (also used in Sweden), Danish and Finish one). They are used in various ways: some institutions might require their researchers to only publish with top rated publishers from these lists, some might use it as a point of reference in evaluating their institution's publishing output, and some might steer their researchers towards them in the search for trustworthy publishers. The lists themselves, as well as practices surrounding the evaluation/inclusion processes remain controversial. According to the Finnish list, operating on a $0-3$ scale $(0=$ under evaluation, $1=$ basic, $2=$ =leading, $3=$ top) there are 13 leading book publishers in the world, with usual suspects included: a bunch of Ivy League university presses and commercial giants like Palgrave 
Macmillan or Routledge. Needless to say, these existing lists present a huge challenge for new/small publishers and new open access books initiatives.

\section{Level up}

Particularly OA-friendly Nordic climate facilitates formation of coalitions that deal with issues of open science. There is a plethora of OA-related umbrella organisations in the Nordic countries: library consortia, associations of learned societies, and national OA initiatives that act as representatives for a collection of stakeholders and institutions. Participants recommended creating liaisons with this existing ecosystem and interacting with national-level collectives in order to gain a broad-scale engagement for the proposed collective funding models for OA books.

\section{Make it easy}

Participants seemed to be interested in supporting a broad collective for OA books funding, a coherent group with a well-defined structure, that could act as a "one stop platform" for them.

One wish that we heard voiced continuously throughout the workshop was that for the ease of interaction. Easiness has several aspects: participants were calling for a user friendly interface, for good quality MARC records and for interoperability with existing library systems. They were all asking for an easy to understand pitch that would clearly explain benefits of a proposed model to researchers and institutions alike. The former group is of particular importance in the Nordic countries where the academic landscape is very much researcher-driven. As the libraries acquisition decisions rely heavily on the needs expressed by researchers themselves, they are the group to be paid a special attention to when developing OA books projects in the North.

\section{Speak our language}

The question of regional needs and sensitivity towards pre-existing structures kept coming back as an important discussion theme. How can one position a new OA books initiative in the context of existing local university presses offering OA options to its researchers? Where would it fit? Would we compete, would we collaborate, would the university presses be included in this new platform that you are developing?-participants were asking.

They also raised the question of multilingualism, pointing out, similarly to what we heard in the Polish workshop, the importance of local languages, especially in the case of Humanities and Social Sciences.

Thank you to all the participants and their feedback: it was a great opportunity to see how OA books related questions are treated in the Nordic countries. 
Our next workshop, similarly to the Scandinavian one, will be geared towards a region rather than a specific country. This time we will travel to the South to talk to OA specialists from Croatia, Slovenia and Greece. We are looking forward to hearing their thoughts on the issue of collective funding models for $O A$ books and the role that their libraries can play in them. Stay tuned for the next report!

Photo of Helsinki Central Library by Siyuant on Flickr, CC BY-NC 2.0 